\section{The 1993 Canadian Association of Gastroenterology Strategic Plan: Excellence in achievement}

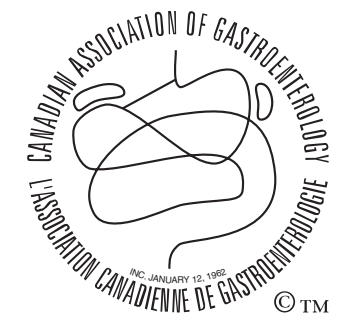

En français voir page 675

\author{
Richard Fedorak MD FRCPC, Past President, CAG \\ Philip Sherman MD FRCPC, President, CAG
}

$\mathrm{B}_{\mathrm{c}}^{\mathrm{s}}$ $y$ the summer of 1990, the Canadian Association of Gastroenterology (CAG) had been in existence as Canada's premier gastroenterology society for nearly thirty years. The specialty of gastroenterology was in an exponential growth phase and many changes were on the horizon, including discussions as to whether the CAG should continue to conduct its annual meeting in conjunction with the Royal College meeting. In 1990, the CAG Governing Board and then president Dr Eldon Shaffer initiated a membership needs analysis (with technical assistance provided through the Strategic Planning Group at Searle Canada Inc) to provide a foundation for a strategic planning process that was to carry forward over the next several years and ultimately produce the CAG's first strategic planning document. After substantial review and assessment, the 1991/1992 and 1992/1993 CAG Governing Boards approved the 1993 CAG Strategic Plan. This strategic plan served the organization well over the past decade and has provided the cornerstone upon which the CAG advanced many progressive initiatives.

As the 2003/2004 CAG Governing Board moves forward with the design and implementation of the 2004 CAG Strategic Planning Document, we believe that it is opportune to review the successes that the CAG has had as a consequence of its first strategic plan. The objectives of the 1993 Strategic Plan and some of the initiatives the CAG has implemented over the last decade to meet these objectives are detailed below.

Strategic Plan 1: Promote research in gut function and digestive diseases

- The CAG Research Committee redefined its objectives and became proactive in seeking research funding.

- Twelve studentships, 14 fellowships, four new investigator awards, and three operating grants were established through the CAG Finance Committee.

- Partnership with industry and the Canadian Institutes of Health Research (CIHR) secured nearly \$1.5 million yearly for research activities conducted by members of the CAG.
- The Canadian Digestive Health Foundation was created to serve as a vehicle to secure additional funding for research, training and education.

Strategic Plan 2: Enhance professional education

- The CAG Education Committee broadened its mandate beyond continuing medical education at the annual general meeting.

- The Canadian Digestive Disease Week (CDDW) was established in 1996, with attendance increasing from 50 per year to over 700 registrants annually.

- With the benefit of a needs analysis, the CDDW Implementation Committee and the CAG Education Committee designed complementary educational programs to meet the requirements of the membership, including:

a. CAG Interactive Lecture Series ( $\mathrm{n}=200$ currently listed);

b. CAG CD-ROM Educational Series ( $\mathrm{n}=18$ currently published);

c. regional CAG-supported continuing professional development programs;

d. Maintenance of Certification (MOCERT) Accreditation Provider Status for the CAG; and

e. restructuring of the CDDW program to meet changing educational needs.

Strategic Plan 3: Develop standards on ethical conduct

- Through the newly established CAG Practice Affairs Committee, more than 10 clinical practice guidelines were constructed and published in the Canadian Journal of Gastroenterology.

- Through the CAG Ethics Committee, the CAG has adopted and supported updated ethics guidelines of the Canadian Medical Association and published recommendations for interactions with our partners in industry.
std.
AstraZeneca Canada Inc.
Axcan Pharma Inc.
Janssen-Ortho Inc. 


\section{Strategic Plan 4: Promote quality health delivery}

- To develop and employ reliable means of evaluating new technologies, therapies and management schemes, the CAG Education Committee implemented and supported national consensus conferences on gastroesophageal reflux disease, inflammatory bowel diseases, and Helicobacter pylori therapies. Through these consensus conferences, leadership roles in delineating cost-benefit relationships of novel treatment strategies were established.

- The CAG Endoscopy Committee reviewed and published extensive guidelines for Training in Endoscopy, Maintenance of Competence and Provision of Endoscopic Standards.

- The CAG Endoscopy Committee established a national database for endoscopy and upper gastrointestinal tract bleeding (the RUGBE program).

\section{Strategic Plan 5: Improve communication amongst the membership}

- The CAG Bylaws were rewritten to reflect the varying needs and goals of the current membership.

- The CAG Admissions Committee doubled membership in the CAG.

- The CAG Nominations Committee was restructured to attract broader regional representation for membership on CAG committees and the CAG executive.

- Clinical sessions at the CDDW were restructured with oral discussion of poster sessions, clinical practice sessions and the implementation of an annual postgraduate course.

- The CAG has sponsored and fostered regional and provincial meetings.

- Regional and provincial representation was established at the level of the CAG Governing Board and on specific CAG committees.

- The CAG Newsletter was published and distributed to all CAG members at regular intervals. Subsequently, through the Canadian Journal of Gastroenterology, a CAG

Newspage was initiated. The Newspage continues to serve to keep members of the CAG informed of the activities of its various committees and the CAG Executive.

- The CAG has endorsed the development of diseaserelated networks such as an Inflammatory Bowel Disease Registry, the Canadian Helicobacter Study Group and an Endoscopy Registry (RUGBE).

Strategic Plan 6: Increase representation to government and national funding agencies

- On a regional basis, the CAG has supported provincial gastrointestinal societies bringing forward issues related to deficiencies or excesses within the discipline.

- The CAG Research Committee has worked to enhance and promote federal and industry cofunding in gastroenterology through the CIHR-Rx\&D program.

- Increasingly, the CAG has worked in partnership with the Crohn's and Colitis Foundation of Canada.

\section{Strategic Plan 7: Enhance the profile of the CAG and} Canadian gastroenterologists

- A bid for the Pan-American Congress was successful, and Gastro '99 was staged in Vancouver during September, 1999. Gastro '99 provided an outstanding opportunity for the CAG to feature its profile on the international stage.

- A bid for the 2002 World Congress of Gastroenterology was placed. Although unsuccessful, the bid highlighted for the international community the excellent facilities, resources and talents that Canadian gastroenterologists have at their disposal.

- A bid for the 2005 World Congress of Gastroenterology was placed and the submission was rewarded with success. The meeting will take place in Montreal on September 10-13, 2005 (www.wcog2005.org).

- The CAG Scholars Program (née Bright Lights) was initiated in 2000 at the CDDW with the intent of attracting the best and brightest trainees into the discipline of gastroenterology.

\section{Strategic Plan 8: Establish a CAG national office}

- In 1994, the CAG initially established a national office with Peter Fletcher and Associates. This office served the organization for five years.

- In 1998, the CAG engaged a part-time Executive Director.

- In 2000, the CAG initiated a search and selection process to establish a full time National Executive Director and a permanent national office in Oakville (contact: cagoffice@ $@_{\text {cag-acg.org) }}$

A subsequent CAG Newspage in this Journal will provide a summary of the findings of the 2002/2003 CAG Needs Assessment Survey. Another will provide a description of the 2004 CAG Strategic Plan, which is currently being developed with the intent of providing a set of priorities and action plans for the coming decade. Please do not hesitate to contact either of us, or any member of the CAG Executive, with your comments, feedback and suggestions. 


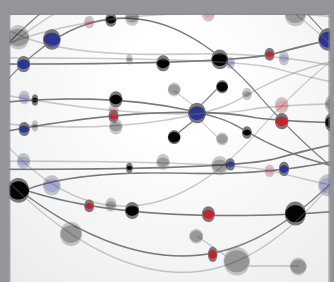

The Scientific World Journal
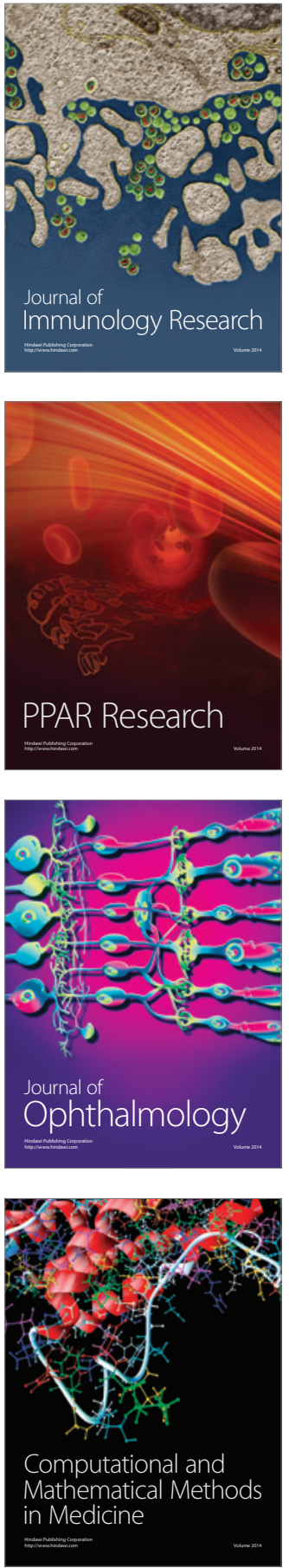

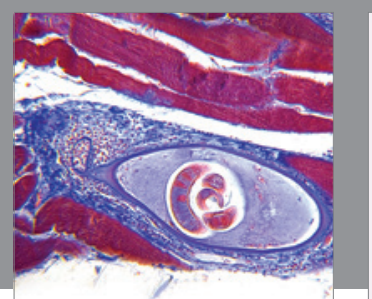

Gastroenterology Research and Practice

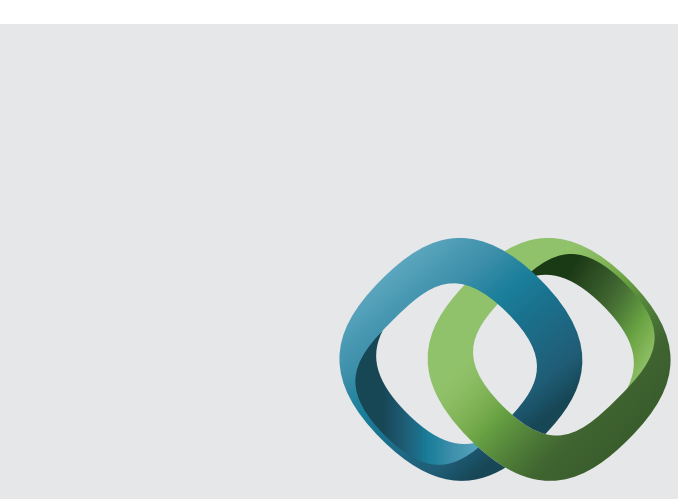

\section{Hindawi}

Submit your manuscripts at

http://www.hindawi.com
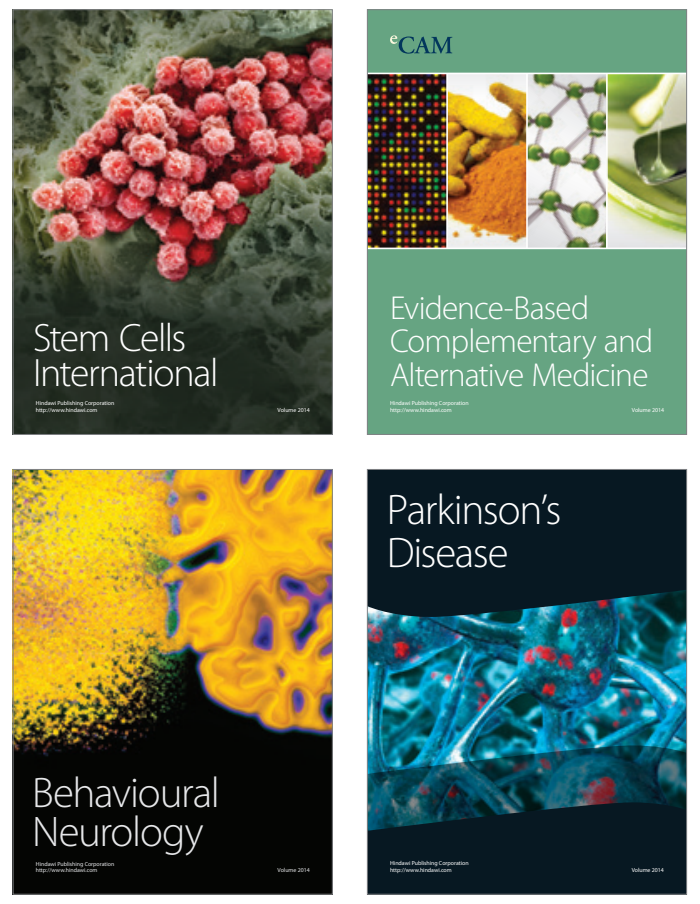
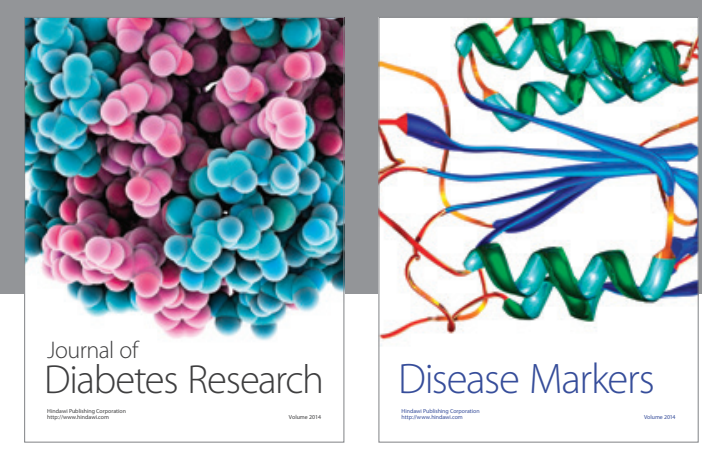

Disease Markers
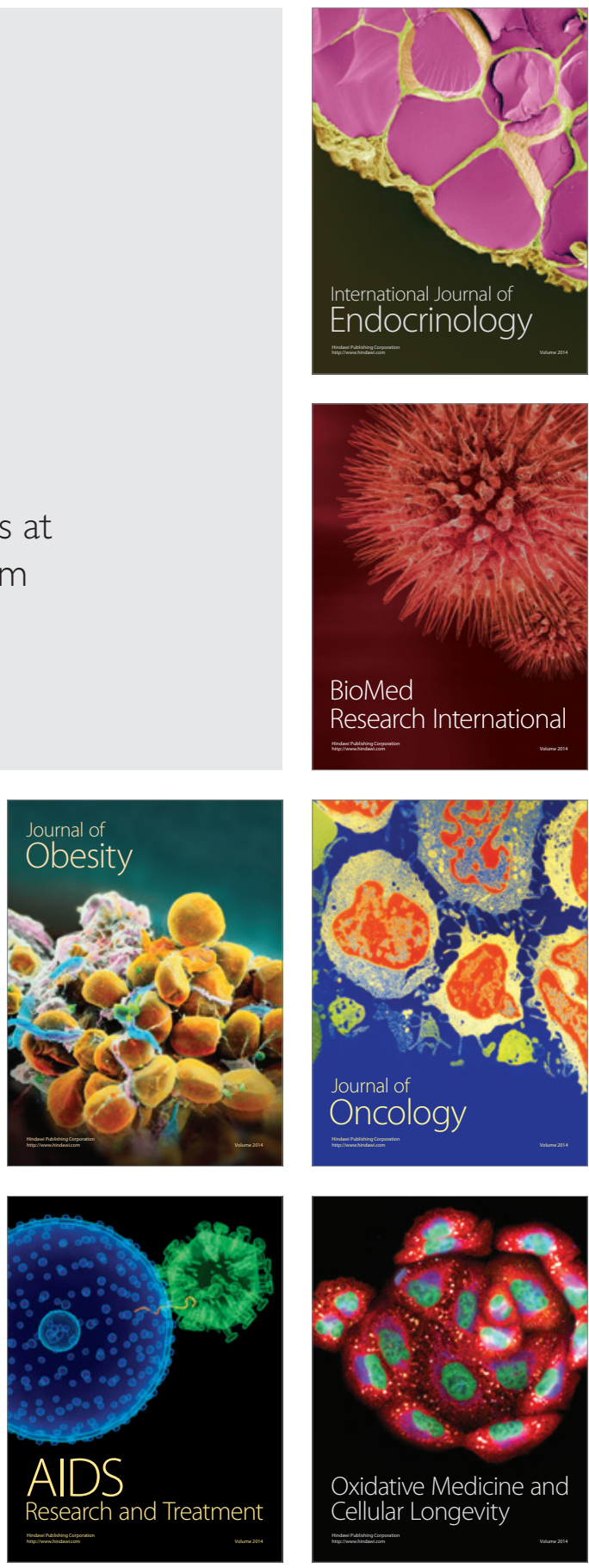